\title{
Comparison of Frequency of Post-Operative Pain in Nerve Excision Vs Nerve Preservation During Inguinal Hernioplasty for Inguinal
} Hernia

Muhammad Nasir, Sajid Rehman Randhawa, Muhammad Saleem lqbal, Muhammad Sohaib Asghar, Muhammad Fasih-ur Rehman, Muhammad Umer Farooq

\section{ABSTRACT}

Objective: To compare the outcome in terms of post-operative pain in cases where ilio-inguinal nerve is sectioned electively with those where nerve is preserved during hernioplasty for primary inguinal hernia. Study Design: Randomized Controlled Trial. Settings: Surgical Units of Allied \& DHQ hospital, Faisalabad Pakistan. Duration: 1 year from Jan 2017 to Dec 2017. Methodology: Approval from ethical review committee was obtained and patients from OPD based on the inclusion criteria were enrolled after informed consent. They were randomly divided into two groups. Patients in Group A had their ilio-inguinal nerve excised whereas it was preserved in patients in Group B. These procedures were performed by senior surgeons. Follow up was done by preserving patients' telephone numbers in protocol proforma. Pain was assessed after 1 month of the procedure. Whole information was added on a Performa. Results: The study showed, mean age in Group A was $28.58 \pm 3.29$ years and $33.8 \pm 8.35$ years in Group B. $85 \%$ of patients $(n=34)$ in Group A were males and $15 \%(n=6)$ were females whereas $77.5 \%(n=31)$ in Group $B$ were males and $22.5 \%(n=9)$ were females. Frequency of post-operative pain in both groups was calculated and it was found that $32.5 \%$ of the patients ( $n=13$ ) in $\mathrm{Group} A$ and $57.5 \%$ ( $n=23$ ) in Group B had pain. On the other hand, $67.5 \%$ of patients $(n=27)$ in Group A and $42.5 \%(n=17)$ in Group B had no pain ( $p$ value $=0.024)$. This demonstrates a clear difference between the two study groups. Conclusion: In the nutshell that the outcome in terms of frequency of post-operative pain is significantly better in cases where ilio-inguinal nerve is sectioned as compared with those where nerve is preserved during hernioplasty for inguinal hernia.

Keywords: Inguinal hernia, Inguinal hernioplasty, Nerve excision, Nerve preservation, Post-operative pain.

Corresponding Author

Submitted for Publication: 19-10-2019

Accepted for Publication: 03-02-2020

DR. MUHAMMAD NASIR, Assistant Professor of Surgery, Faisalabad Medical University, Faisalabad-Pakistan

Contact / Email: +92 323-6037345, mnasirhaleemamedicare@gmail.com

Citation: Nasir M, Randhawa SR, Iqbal MS, Asghar MS, Rehman MF, Farooq MU. Comparison of Frequency of Post-Operative Pain in Nerve

Excision Vs Nerve Preservation During Inguinal Hernioplasty for Inguinal Hernia. APMC 2020;14(1):16-9.

\section{INTRODUCTION}

Surgery for hernia repair has a rich history and surgeons, since ancient times, have endeavored to improve upon it. $A$ successful repair of inguinal hernia requires a sound understanding of surgical anatomy of the groin region. Hernioplasty is a common general surgical procedure and in US alone, about 700,000 hernia operations are performed each year. ${ }^{1}$ This figure is increasing as the incidence of hernia continues to rise. Groin pain is one of the unsolved problems after hernia surgery especially when prosthetic material (mesh) is used. ${ }^{2}$ It is not uncommon and occurs with a prevalence of $15 \%-53 \%{ }^{3}$ The visual analog score for pain on 1 st postoperative day after hernioplasty ranges between 2 and 5.4 It is thought to result from peri-operative nerve damage, postoperative fibrosis, or mesh-related fibrosis. The reasons may be classified as either neuropathic or non-neuropathic pain. ${ }^{1}$ Three nerves including llio-inguinal (IIN), llio-hypogastric (IHN) and genital branch of the genitofemoral nerve (GFN) have been incriminated. ${ }^{5}$ Damage to these nerves, by trauma during dissection or retraction of tissues, or nerve entrapment from post-operative or mesh-related fibrosis or sutures used to fix the mesh may be responsible. ${ }^{6}$

European Federation of Neurological Societies (EFNS) recommends medical management and the use of neuropathic pain medications such as gabapentin and tricyclic antidepressants for the treatment of "traumatic and postsurgical neuropathic pain". More invasive therapeutic interventions using local anesthetic and corticosteroids for ilio-inguinal/ iliohypogastric nerve blocks (IINBs) can be effective in treating pain non-responsive to medical management. ${ }^{3}$

Surgeons usually try to preserve the nerve because of the presumed morbidity associated with loss of cutaneous sensation and chronic groin pain following nerve injury, 7,8 but recent studies have explored the results of intentional severance based on the concept of "no nerve, no pain". ${ }^{8}$ llioinguinal neurectomy, however, is an effective treatment for treatment of chronic groin pain following open repair hernia. ${ }^{7}$ In one study, $63.6 \%$ patients had no pain after 1 month of nerve excision and $35.2 \%$ patients with nerve preservation ( $p$ value $=0.001) .{ }^{7} \mathrm{~A}$ meta-analysis by Mui et al concluded that there is no significant difference in frequency of post-operative pain after 1 month between two groups $(78.7 \%$ in nerve excision \& $78.7 \%$ in nerve preservation). ${ }^{5}$

Thus, there is conflicting evidence in literature regarding the role of nerve preservation or excision during inguinal hernioplasty. So, the results of our study will strengthen the evidence in favor of elective nerve sectioning during surgery for the prevention of chronic painful groin after inguinal hernioplasty. 
The aim of this study was to compare the results in terms of chronic groin pain in cases where ilio-inguinal nerve is sectioned electively with those where nerve is preserved during hernioplasty for primary inguinal hernia.

\section{OPERATIONAL DEFINITION}

Primary Inguinal Hernia: It was assigned to the patients who had swelling in the right or left inguinal and scrotal areas. On examination, the swelling was reducible with positive cough impulse (increase in size of swelling with coughing). It was only a clinical diagnosis and no radiological test is required.

Chronic Groin Pain: It was measured after 1 month of surgery by using visual analogue scale which is a $10 \mathrm{~cm}$ vertical score ranged from "0 (no pain)" to "10 (worst pain)". Pain was considered when VAS $\geq 4$.

\section{METHODOLOGY}

Study Design: Randomized Controlled Trial.

Settings: Surgical Units in Allied \& DHQ Hospitals, Faisalabad Pakistan.

Duration: 1 year from Jan 2017 to Dec 2017.

Sample Size:

- By using WHO sample size calculator for 2 proportion

- $\mathrm{P} 1=63.6 \%$

- $\mathrm{P} 2=35.2 \% 6$

- Power of study $=80 \%$

- Level of significance $=5 \%$

- Sample size $=80$ (40 in each group)

Sampling Technique: Non probability consecutive sampling. Inclusion Criteria: Age of patients from 18 - 60 years of both genders. Patients undergoing for inguinal hernioplasty for primary inguinal hernia as per operational definition.

Exclusion Criteria: Patients with obstructed / strangulated hernia. Patients with recurrent hernia. Immunocompromised patients like diabetes mellitus and HIVIAIDS.

Methods: After approval from PMC ethical review committee, patients from OPD fulfilling the inclusion criteria and giving consent were enrolled. All the patients were randomly divided into two groups by using computer generated randomly assigned number. In group $A$, patients underwent ilioinguinal nerve excision and in group $B$, patients underwent ilioinguinal nerve preservation. These procedures were performed by senior surgeon. Telephone number of the patients was obtained and saved. Follow up was arranged by contacting them and pain was assessed after 1 month of procedure as per operational definition. All the information was collected on a specially designed Performa.

Data Analysis: SPSS version 20 was used for analysis of data. Descriptive statistics including mean and standard deviation of numerical values like age and BMI. Frequency and percentage were calculated for all qualitative variables like gender and postoperative pain. Post-operative pain was compared by using chisquare test between both groups. Effect modifiers like age and gender, BMI were controlled by stratification. Post stratification chi-square test was applied. P-value $<0.05$ was considered significant.

\section{RESULTS}

Total 80 cases (40 in each group) satisfying the inclusion criteria were enter in to study to compare the frequency of postoperative pain.

Age distribution: It shows that $57.5 \%(n=31)$ in Group-A and $52.5 \%(n=21)$ in Group-B were between 18-35 years of age while $42.5 \%(n=9)$ in Group-A and $47.5 \%(n=19)$ in Group-B were between 36-60 year of age, mean \pm SD was calculated as $28.58 \pm 3.29$ years in Group $-A$ and $33.8+8.35$ years in Group-B.

Table 1: Age distribution $(\mathrm{N}=80)$

\begin{tabular}{|c|c|c|c|c|}
\hline \multirow{2}{*}{$\begin{array}{c}\text { Age } \\
\text { (in years) }\end{array}$} & \multicolumn{2}{|c|}{ Group A ( $\mathbf{n = 4 0 )}$} & \multicolumn{2}{c|}{ Group B ( $\mathbf{n = 4 0 )}$} \\
\cline { 2 - 5 } & No. of patients & $\%$ & No. of patients & $\%$ \\
\hline $18-35$ & 31 & 57.5 & 21 & 52.5 \\
\hline $36-60$ & 9 & 42.5 & 19 & 47.5 \\
\hline Total & $\mathbf{4 0}$ & 100 & 40 & 100 \\
\hline Mean+SD & $28.58 \pm 3.29$ & \multicolumn{3}{|c}{$33.8+8.35$} \\
\hline
\end{tabular}

Gender distribution: $85 \%(n=34)$ in Group-A \& $77.5 \%(n=31)$ in Group-B were male whereas $15 \%(n=6)$ in Group-A and $22.5 \%(n=9)$ in Group-B were females.

Table 2: Gender distribution $(\mathrm{N}=80)$

\begin{tabular}{|c|c|c|c|c|}
\hline \multirow{2}{*}{ Gender } & \multicolumn{2}{|c|}{ Group A $(\mathbf{n}=\mathbf{4 0})$} & \multicolumn{2}{c|}{ Group B ( $\mathbf{n = 4 0})$} \\
\cline { 2 - 5 } & No. of patients & $\%$ & No. of patients & $\%$ \\
\hline Male & 34 & 85 & 31 & 77.5 \\
\hline Female & 6 & 15 & 9 & 22.5 \\
\hline Total & 40 & 100 & 40 & 100 \\
\hline
\end{tabular}

Mean BMI: $28.78+3.29$ in Group-A 28.45+3.22 and in Group-B.

Table 3: Mean BMI of the patients( $\mathrm{N}=80)$

\begin{tabular}{|c|c|c|c|c|}
\hline \multirow{2}{*}{ BMI } & \multicolumn{2}{|c|}{ Group A ( $\mathbf{n}=40)$} & \multicolumn{2}{c|}{ Group B (n=40) } \\
\cline { 2 - 5 } & Mean & SD & Mean & SD \\
\cline { 2 - 5 } & 28.78 & 3.29 & 28.45 & 3.22 \\
\hline
\end{tabular}

Comparison of post-operative pain: In nerve excision vs nerve preservation after inguinal hernioplasty for primary inguinal hernia was done, it shows that $32.5 \%(n=13)$ in Group$A$ and $57.5 \%(n=23)$ in Group-B had pain while remaining $67.5 \%(n=27)$ in Group-A and $42 . \%(n=17)$ in Group-B had no pain, $p$ value was 0.024 showing a significant difference.

Table 4: Comparison of post-operative pain $(\mathrm{N}=80)$

\begin{tabular}{|c|c|c|c|c|}
\hline \multirow{2}{*}{$\begin{array}{c}\text { Post- } \\
\text { operative } \\
\text { pain }\end{array}$} & \multicolumn{2}{|c|}{ Group A (n=40) } & \multicolumn{2}{c|}{ Group B ( $\mathbf{n = 4 0 )}$} \\
\cline { 2 - 5 } & No. of patients & $\%$ & No. of patients & $\%$ \\
\hline Yes & 13 & 32.5 & 23 & 57.5 \\
\hline No & 27 & 67.5 & 17 & 42.5 \\
\hline Total & 40 & 100 & 40 & 100 \\
\hline
\end{tabular}

$P$ value $=0.024$

www.apmcfmu.com 17 
Effect modifiers like age and gender, BMI were controlled by stratification. Post stratification chi-square test was applied. Pvalue $\leq 0.05$ was considered significant. (Table No. 5-7)

Table 5: Stratification for post-operative pain with regards to age $(\mathrm{N}=80)$

AGE: $18-40$ years

\begin{tabular}{|c|c|c|c|}
\hline \multirow{2}{*}{ Group } & \multicolumn{2}{|c|}{ Post-operative pain } & \multirow{2}{*}{ P value } \\
\cline { 2 - 3 } & Yes & No & \multirow{2}{*}{0.07} \\
\hline A & 10 & 21 & \multirow{2}{*}{0.07} \\
\hline B & 12 & 9 & \\
\hline
\end{tabular}

AGE: 41-60 years

\begin{tabular}{|c|c|c|c|}
\hline \multirow{2}{*}{ Group } & \multicolumn{2}{|c|}{ Post-operative pain } & \multirow{2}{*}{ P value } \\
\cline { 2 - 3 } & Yes & No & \multirow{2}{*}{0.22} \\
\hline A & 3 & 6 & \multirow{2}{*}{0.2} \\
\hline B & 11 & 8 & \\
\hline
\end{tabular}

Table 6: Stratification for post-operative pain with regards to gender $(\mathrm{N}=80)$

Male

\begin{tabular}{|c|c|c|c|}
\hline \multirow{2}{*}{ Group } & \multicolumn{2}{|c|}{ Post-operative pain } & \multirow{2}{*}{ P value } \\
\cline { 2 - 3 } & Yes & No & \multirow{2}{*}{0.11} \\
\hline A & 12 & 22 & \\
\hline B & 17 & 14 & \\
\hline
\end{tabular}

Female

\begin{tabular}{|c|c|c|c|}
\hline \multirow{2}{*}{ Group } & \multicolumn{2}{|c|}{ Post-operative pain } & \multirow{2}{*}{ P value } \\
\cline { 2 - 3 } & Yes & No & \multirow{2}{*}{0.05} \\
\hline A & 1 & 5 & \multirow{2}{*}{0.} \\
\hline B & 6 & 3 & \\
\hline
\end{tabular}

Table 7: Stratification for post-operative pain with regards to $\mathrm{BMI}(\mathrm{n}=80)$

$<30$

\begin{tabular}{|l|l|l|l|}
\hline \multirow{2}{*}{ Group } & \multicolumn{2}{|l|}{ Post-operative pain } & P value \\
\cline { 2 - 3 } & Yes & No & \multirow{3}{*}{0.57} \\
\hline $\mathrm{A}$ & 11 & 15 & \\
\hline $\mathrm{B}$ & 14 & 14 & \\
\hline
\end{tabular}

$>30$

\begin{tabular}{|c|c|c|c|}
\hline \multirow{2}{*}{ Group } & \multicolumn{2}{|c|}{ Post-operative pain } & \multirow{2}{*}{ P value } \\
\cline { 2 - 3 } & Yes & No & \multirow{2}{*}{0} \\
\hline A & 2 & 12 & 0.001 \\
\hline B & 9 & 3 & \\
\hline
\end{tabular}

\section{DISCUSSION}

Tender groin after inguinal hernia surgery is a troublesome problem. It represents a therapeutic challenge for the surgeons. Pain due to entrapment of the ilioinguinal, iliohypogastric or genital branch of the genitofemoral nerve either in scar tissue or mesh or sutures, have been proposed as the mechanism for this pain. Preservation/division of the genital nerve have been attempted to avoid pain. Literature does not support the lower incidence of chronic pain with careful preservation of illioinguinal nerve.

The reason to conduct this study was that there is controversy in literature regarding the nerve preservation or nerve excision after inguinal hernioplasty. However, the results of our study are helpful in emphasizing a proper treatment modality for the management of post-operative pain after inguinal hernioplasty as a first line of treatment.

In this study, mean age was calculated as $28.58+3.29$ years in Group A and 33.8+8.35 years in Group B, 85\% $(n=34)$ in Group $A$ and $77.5 \%(n=31)$ in Group $B$ were male whereas $15 \%(n=6)$ in Group $A$ and $22.5 \%(n=9)$ in Group B were females. Frequency of chronic groin pain in nerve excision with nerve preservation was calculated and results compared which showed that $32.5 \%(n=13)$ in Group $A$ and $57.5 \%(n=23)$ in Group B had pain while remaining $67.5 \%(n=27)$ in Group $A$ and $42 . \%(n=17)$ in Group B had no pain. P-value was 0.024 showing a significant difference.

The above findings are in agreement with a study, showing $63.6 \%$ patients had no pain after 1 month of nerve excision and $35.2 \%$ patients with nerve preservation ( $p$-value $=0.001) .{ }^{7}$ Our findings are in contrast with a meta-analysis by Mui et al which showed no significant difference in both the groups $(78.7 \%$ in nerve excision \& $78.7 \%$ in nerve preservation). ${ }^{6}$

Another study ${ }^{8}$ revealed that postoperative pain after inguinal hernioplasty significantly decreases in patients having elective division of ilioinguinal nerve as compared with nerve preservation group.

Another study ${ }^{9}$ randomized ninety-seven consecutive patients into nerve division and preservation groups. They found reduced intensity of mild to moderate chronic groin pain after six months in prophylactic nerve division group as compared to preservation group.

Dittrick and co-workers retrospectively reviewed the outcome of nerve excision or preservation in ninety patients underwent mesh hernioplasty. ${ }^{11}$ They encountered significantly lower incidence of neuralgia in patients who had neurectomy versus nerve preservation group ( $3 \%$ versus $26 \%, p<0.001$ ).

Tsakayannis and colleagues ${ }^{12}$ observed no persistent groin pain in their prospective trial of ilioinguinal and iliohypogastric neurectomy after hernia surgery. They concluded that elective division of ilio-inguinal nerve is safe, well tolerated procedure and is associated with significant reduction in the chronic groin pain in postoperative period.

Prophylactic ilioinguinal neurectomy is associated with significant reduction in postoperative groin pain.

We are of the view that postoperative pain after inguinal hernioplasty significantly decreases in elective division of ilioinguinal nerve as compared to nerve preservation. Therefore, this management strategy should be routinely practiced in reducing postoperative pain after mesh hernioplasty. 


\section{LIMITATIONS}

It has limitation for recurrent hernia.

\section{CONCLUSION}

We concluded that the frequency of post-operative pain in nerve excision group is significantly lower when compared with nerve preservation after inguinal hernioplasty for primary inguinal hernia.

\section{SUGGESTIONS / RECOMMENDATIONS}

This procedure should also be practiced in other departments of surgery because it has good outcome.

\section{CONFLICT OF INTEREST / DISCLOSURE}

There is no conflict of interest involved.

\section{ACKNOWLEDGEMENTS}

Special thanks to Dr Rehman Gulzar Head of Surgical-V for valuable support and guidelines. All the postgraduate residents and house officers were helpful in performing this study.

\section{REFERENCES}

1. Salma U, Ahmed I, Ishtiaq S. A comparison of post-operative pain and hospital stay between Lichtenstein's repair and laparoscopic transabdominal preperitoneal (TAPP) repair of inguinal hernia: a randomized controlled trial. Pak J Med Sci. 2015;31(5):1062-6.

2. Donati M, Brancato G, Giglio A, Biondi A, Basile F, Donati A. Incidence of pain after inguinal hernia repair in the elderly. A retrospective historical cohort evaluation of 18-years' experience with a mesh \& plug inguinal hernia repair method on about 3000 patients. BMC Surg. 2013;13(2):19.
3. Trainor D, Moeschler S, Pingree M, Hoelzer B, Wang Z, Mauck W. Landmark-based versus ultrasound-guided ilioinguinal / iliohypogastric nerve blocks in the treatment of chronic postherniorrhaphy groin pain: a retrospective study. J Pain Res. 2015;8:767-70.

4. Zannoni M, Luzietti E, Viani L, Nisi P, Caramatti C, Sianesi M. Wide resection of inguinal nerves versus simple section to prevent postoperative pain after prosthetic inguinal hernioplasty: our experience. World J Surg. 2014;38(5):1037-43.

5. Hsu W, Chen CS, Lee HC, Liang HH, Kuo LJ, Wei PL. Preservation versus division of ilioinguinal nerve on open mesh repair of inguinal hernia: a meta-analysis of randomized controlled trials. World J Surg. 2012;36(10):2311-9.

6. Nasir I, Iftikhar M, Aslam R, Alam J. Chronic postoperative pain following groin hernia repair: a comparison between nerve preservation and nerve excision. KJMS. 2014;7(2):226-30.

7. Burcharth J, Pedersen M, Bisgarrd T, Pedersen C, Rosenberg J. Nationwide prevalence of groin hernia repair. PLoS one. 2013;8(1):e54367.

8. Beard JH, Oresanya LB, Akoko L, Mwanga A, Dicker RA. An estimation of inguinal hernia epidemiology adjusted for population age structure in Tanzania. Hernia. 2014;18(2):289-95.

9. Fitzgibbons RJR. Forse AR Groin Hernias in Adults. N Engl J Med. 2015;372(8):756-63.

10. Jatoi AH, Younus SM, Ghayassuddin M, Mirani AJ, Ghayas N, Qazi A, Suchdev S, Bakhsi S. Postoperative pain; comparison after preservation and elective division of ilioinguinal nerve in inguinal hernioplasty. Professional Med J. 2014;21(3):559-65.

11. Dittrick GW, Ridl K, Kuhn JA, McCarty TM (2004) Routine ilioinguinal nerve excision in inguinal hernia repairs. Am J Surg 188:736-40.

12. Tsakayannis DE, Kiriakopoulos AC, Linos DA. Elective neurectomy during open, "tension free" inguinal hernia repair. Hernia. 2004;8:67-9.

\section{AUTHORSHIP AND CONTRIBUTION DECLARATION}

\begin{tabular}{lc} 
AUTHORS & Contribution to The Paper \\
\hline $\begin{array}{l}\text { Dr. Muhammad Nasir } \\
\text { Assistant Professor of Surgery } \\
\text { Faisalabad Medical University, Faisalabad Pakistan }\end{array}$ & Idea Conceived \\
\hline $\begin{array}{l}\text { Dr. Sajid Rehman Randhawa } \\
\text { Associate Professor Surgery } \\
\text { Faisalabad Medical University, Faisalabad Pakistan }\end{array}$ & Literature Review \\
\hline $\begin{array}{l}\text { Dr. Muhammad Saleem Iqbal } \\
\text { Assistant Professor of Surgery } \\
\text { Faisalabad Medical University, Faisalabad Pakistan }\end{array}$ & Data Analysis \\
\hline $\begin{array}{l}\text { Dr. Muhammad Sohaib Asghar } \\
\text { Post Graduate Resident, Surgical Unit-V } \\
\text { DHQ Hospital, Faisalabad Pakistan }\end{array}$ & Data Collection \\
\hline $\begin{array}{l}\text { Dr. Muhammad Fasih-ur Rehman } \\
\text { Senior Registrar, Surgical Unit-V } \\
\text { DHQ Hospital, Faisalabad Pakistan }\end{array}$ & Proof Reading \& References \\
\hline $\begin{array}{l}\text { Dr. Muhammad Umer Farooq } \\
\text { Senior Registrar, Surgical Unit-V } \\
\text { DHQ Hospital, Faisalabad Pakistan }\end{array}$ & Final Editing and Discussion
\end{tabular}

